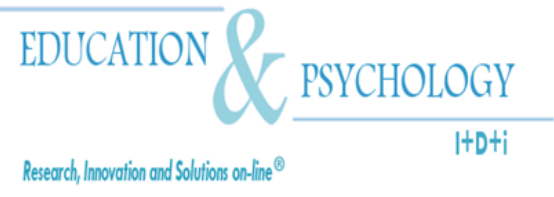

\title{
Exploring the effects of changes in future time perspective and perceived instrumentality on graded performance
}

\author{
Altay Eren \\ Department of Educational Sciences, Abant Izzet Baysal University, Bolu
}

Turkey

Correspondence: Altay Eren. Abant İzzet Baysal University, Faculty of Education, Department of Educational Sciences, 14280 Gölköy Campus, Bolu, Turkey. E-mail: eren_a@ibu.edu.tr

(C) Education \& Psychology $\mathrm{I}+\mathrm{D}+\mathrm{i}$ and Editorial EOS (Spain) 


\begin{abstract}
Introduction. This study aimed to explore the possible changes in the Future Time Perspective (FTP) and Perceived Instrumentality (PI) over time as long as one academic semester, as well as to explore whether those changes in FTP and PI explained students' Graded Performance (GP) with regard to a specific course; educational psychology.
\end{abstract}

Method. A total of 188 undergraduate students participated in the study. Both classical statistical techniques and the Reliable Change Index were used to examine the possible changes in FTP and PI, whereas the Hierarchical Regression and Structural Equation Modeling (SEM) analyses were used to examine the effects of those changes in FTP and PI on GP.

Results. The results showed that for the majority of the students FTP and PI significantly changed, while they remained stable for others within the sample over one academic semester, signifying that the concepts of FTP-change and PI-change are more complex than it has been assumed to date in educational settings. However, those changes in FTP and PI did not explain GP with regard to the Educational Psychology course. Furthermore, while there was no observed significant age and gender effect on GP, a significant lecturer effect was observed.

Conclusion. This effect was confirmed by the results of the SEM analysis. Educational implications and directions for future research were also discussed.

Keywords: Future time perspective; Perceived instrumentality; Graded performance; Undergraduate students

Received: 04/21/09 Initial Acceptance: 04/28/09 Final Acceptance: 10/08/09 


\section{Exploración de los efectos de cambios en la perspectiva del tiempo futuro, y de la instrumentalidad percibida, sobre rendimiento cualificado}

\section{Resumen}

Introducción. El estudio tiene por objetivo explorer los posibles cambios en la Perspectiva del Tiempo Futuro (PTF) y en la Instrumentalidad Percibida (IP) a lo largo de todo un semestre académico. Del mismo modo, pretende explorar si los cambios producidos en la PTF y la IP explican el Grado de Ejecución (GE) de los estudiantes en relación con una asignatura específica, psicología de la educación.

Método. Un total de 188 estudiantes no graduados participaron en este estudio. Para examinar los posibles cambios en PTF e IP se utilizaron técnicas estadísticas clásicos y el Índice Real de Cambio, mientras que la Regresión Jerárquica y los modelos de ecuaciones estructurales (MEE) fuero usado para examinar los efectos de las variables FTP e IP sobre la variable GE.

Resultados. Los resultados muestran que la mayor parte de los estudiantes modifican su PTF e PI de forma significativa mientras que en el resto se mantienen estables a lo largo el semestre, lo que indica que los conceptos de cambio de PTF e IP son más complejos que lo que ha sido asumido en los diseños educativos. Sin embargo, los cambios en PTF e IP no explican el GE en relación con la asignatura de Psicología de la Educación. Además, no se observa efectos significativos de la edad y el sexo en el grado de ejecución, aunque se observa un efecto significativo del profesor.

Conclusion. El análisis mediante modelos de ecuaciones estructurales confirma un efecto significativo por parte del profesorado. Se discuten algunas implicaciones educativas y directrices para futuras investigaciones.

Palabras Clave: Perpectiva del Tiempo Futuro; Instrumentalidad Percibida; Grado de Ejecución; pre-graduados.

Recibido: 21/04/09 Aceptación inicial: 28/04/09 Aceptación final: 08/10/09 


\section{Introduction}

The Future Time Perspective (FTP), which is the ability to foresee and anticipate, to make plans for and organize future possibilities (Seijts, 1998), is one of the important aspects of the human cognitive system (Toda, 1983; Zimbardo \& Boyd, 2008). As such, FTP provides a solid basis for setting personal goals and planning life spans, exploring future options, and carrying out major decisions, which, in turn, may affect the individual's life course in particular ways (Leonardi, 2007). Because of its important role in human life, individuals' perceptions about the future has long been investigated in different lines of research such as substance use (Apostolidis, Fieulaine, \& Soulé, 2006), forestry (Hoogstra \& Schanz, 2008), procrastination (Ferrari \& Diaz-Morales, 2007), social relationships (Lang \& Carstensen, 2002), and education (Adelabu, 2007; De Volder \& Lens, 1982; Husman \& Lens, 1999; Miller, DeBacker, \& Greene, 1999; Shell \& Husman, 2008; Simons, Dewite, \& Lens, 2004) as well as along with various conceptions such as future time orientation (Gjesme, 1983), time perspective (Kauffman \& Husman, 2004; Zimbardo \& Boyd, 1999), and temporally extendedself (Moore \& Lemmon, 2001). Although these conceptualizations differ from one another (Gjesme, 1983; Lewin, 1951; Wallace, 1956), they refer to individuals' perceptions about the future, or more specifically, refer to individuals' ability to consider future in order to achieve their goals at hand, which has widely been examined under the heading of FTP (Husman \& Shell, 2008).

On the other hand, Perceived Instrumentality (PI), which is one of the core elements in expectancy-value theories of motivation (e.g., Eccles, Wigfield, \& Schiefele, 1998; Vroom, 1964; Wigfield \& Eccles, 2000), refers to the task-specific aspect of FTP. The expectancyvalue theory of motivation predicts that individuals' choice, persistence, and performance can be explained by both their beliefs about how well they will do on the activity and the extent to which they value the activity (Wigfield \& Eccles, 2000). Accordingly, individuals' goalrelated behaviors can be explained as a function of their goal-related future expectancies and the extent to which they value their future goals (Lens, 2001). Accordingly, PI is when a person recognizes that the current endeavor supports or is instrumental to achieving a valued future goal (Bembenutty, 2009; Greene \& DeBacker, 2004).

A large body of research showed that both FTP and PI significantly predict adaptive educational outcomes such as student motivation and achievement (De Volder \& Lens, 1982; 
Malka \& Covington, 2005; Miller et al., 1999; Simons et al., 2004; Simons, Vansteenkiste, Lens, \& Lacante, 2004). Furthermore, research on age differences in FTP showed that younger people are more future-oriented than older people (Cate \& John, 2007; Lang \& Carstensen, 2002; Padawer, Lawson, Hershey, \& Thomas, 2007), suggesting that FTP is not fixed, but malleable by nature. The same is also true for PI because its task-specific or contextual nature makes PI more open to the effects of environment. However, the current literature lacks longitudinal studies in which the effects of FTP and PI on Graded Performance (GP) have simultaneously been investigated. Therefore, it is not known whether or not those effects of FTP and PI on GP originate from the effects of changes in either FTP/PI or of changes in both FTP and PI. In other words, the question of whether those changes in FTP and PI affect GP has remained to be investigated.

In fact, our knowledge about the roles of FTP and PI in student motivation and achievement has largely been based on the results of cross-sectional studies (e.g., Simons et al., 2004). Although these studies provide substantial evidence stating that both FTP and PI are effective on student motivation and achievement, they do not provide an explanation regarding the question of 'do possible changes in students' FTP and PI make them more motivated and successful in educational settings?' Or 'do possible changes in student motivation and achievement make them more FTP and PI-oriented?' More importantly, Zimbardo and Boyd (2008) recently argued that FTP and PI are not fixed, but malleable by nature. This highlights the importance of a longitudinal design through which the relationships among FTP, PI, and achievement are explored by examining the effects of possible changes in students' FTP and PI on their course achievement. As known, a longitudinal design is more appropriate than a cross-sectional design in order to consider the malleable nature of the variables at hand (see, for example, Neuman, 2006 for a comprehensive explanation).

Additionally, to focus on both a relatively short period of time such as one academic semester and one specific course such as educational psychology has also the potential to reveal a possible teacher/lecturer effect on changes in FTP and PI, which, in turn, may provide more meaningful and comprehensive view regarding the well-evidenced relationships among FTP, PI, and GP. Therefore, this study focused on both changes in FTP/PI and the effects of those changes in FTP/PI on GP. Relevant concepts were summarized below. 


\section{Structure of the Future Time Perspective}

A considerable amount of research demonstrated that FTP is not a unidimensional, but a multidimensional construct (Daltrey \& Langer, 1984; Husman \& Shell, 2008; Shell \& Husman, 2001; Zimbardo \& Boyd, 1999). Specifically, researchers have identified different dimensions of FTP such as valance or value - the degree to which people attribute importance to future goals (De Volder \& Lens, 1982); connectedness - "the ability to make connections between present activities and future goals" (Husman \& Shell, 2008, p. 167); extension - the subjective time horizon by which people's forethought is limited (Daltrey \& Langer, 1984); coherence - the degree of organization of the events in the future time span (Seijts, 1998); and speed - a subjective feeling about how fast the time is passing (Husman \& Shell, 2008).

The extension, coherence, speed, and the connectedness are cognitive aspects of FTP (Seijts, 1998) whereas value is an affective aspect - the extent to which a person is gratified by anticipated events (Seijts, 1998). Although some of these aspects of FTP were considered with different viewpoints in previous studies (De Volder \& Lens, 1982; Gjesme, 1983; Husman \& Lens, 1999; Husman \& Shell, 2008; Shell \& Husman, 2001; Seijts, 1998; Stouthard \& Peetsma, 1999; Zimbardo \& Boyd, 1999), there is only one study in which most of these aspects were considered under the heading of FTP. Based on the sample of undergraduate students, and using both exploratory and confirmatory factor analyses, Husman and Shell (2008) developed a FTP scale that captures the value, extension, speed, and the connectedness dimensions of FTP. The results of their study revealed that FTP can well be represented with these aspects.

On the other hand, the PI was conceptualized as a part of the FTP (Malka \& Covington, 2005). Gjesme (1983), for instance, suggested that it is necessary to differentiate between general and specific forms of FTP (future time orientation in terms of Gjesme) because these constructs vary by their scope (i.e., long-term or short-term) and their range of content (i.e., global or task specific). Thus, Gjesme (1983) defined PI as a task-specific form of FTP. Recent research has confirmed that task-specific FTP (i.e., PI) is related to, but distinct from the global form of FTP (i.e., value and connectedness) (Lens, 2001; Malka \& Covington, 2005).

Finally, it has long been acknowledged that culture affects FTP. In other words, individuals' FTP is not independent from their socialization processes in particular and their culture in general (Bentley, 1983; Meade, 1972; Phan, 2009), signifying that different aspects of 
FTP may emerge in different cultures. For example, based on a large sample of Turkish undergraduate students $(n=721)$, Eren (2007) carried out a study in which factor structure of the FTP scale (Husman \& Shell, 2008) was investigated through both exploratory and confirmatory factor analyses. He found that not the four-factor structure (i.e., connectedness, value, extension, and speed) with 27 indicators, but the two-factor structure (i.e., connectedness and value) with 14 indicators was confirmed. Eren (2007) concluded that the socio-cultural and socio-economic differences between North American and Turkish undergraduate students may play a significant role in explaining the observed difference in the structure of the Turkish version of the FTP scale.

In the present study, the FTP-value and FTP-connectedness dimensions were considered in order to examine the undergraduate students' FTP. There were two important reasons for the mentioned consideration. First, these dimensions have been found to be of particular relevance to academic achievement in general, course achievement in particular (e.g., Malka \& Covington, 2005; Shell \& Husman, 2008). Second, as mentioned above, Eren (2007) recently demonstrated that it was not the extension and speed dimensions of the FTP scale, but the value and the connectedness dimensions that were confirmed on a sample of Turkish undergraduate students, indicating that it is more appropriate to use the Turkish version of the FTP scale in order to consider the observed difference regarding the structure of the FTP scale (see Phan, 2009 for a comprehensive review regarding the effects of sociocultural context on FTP).

\section{Literature Review}

Previous studies have shown that both FTP and PI are related with important educational variables such as student motivation (Creten, Lens, \& Simons, \& 2001; Husman \& Lens, 1999; Simons et al., 2004; Simons, Dewite, \& Lens, 2004), school investment (Peetsma, 2000), academic engagement (Horstmanshof \& Zimitat, 2007), and academic achievement (Adelabu, 2007; De Volder \& Lens, 1982; Malka \& Covington, 2005; Teahan, 1958; Zimbardo \& Boyd, 1999). In one of the earlier studies, Teahan (1958), for example, found that high achievers have more extensive (i.e., refers to the subjective time horizon by which people's forethought is limited) FTP than low achievers on most of the projective tests such as story completion tests and Thematic Apperception Tests. On the basis of the distinction between cognitive (i.e., connectedness) and dynamic (i.e., valance) aspects of FTP, De Volder and Lens (1982) demonstrated that students' motivational level (i.e., academic en- 
gagement) and the length of their FTP were significantly and positively correlated with one another, indicating that highly motivated students attributed more value to distant goals and saw their schoolwork more instrumental in order to reach near and distant goals than their less motivated peers. They also found that the higher the students' GPA, the higher the degree of the value that students attributed to distant goals, indicating that students' academic achievement could be explained, at least partly, by how valuable the distant goals were perceived. On the basis of the research reviewed in their study, Husman and Lens (1999) concluded that PI is associated with student motivation (i.e., intrinsic motivation, interest in learning, and achievement goals), and PI is most powerful when it is connected with values.

Moving one step further, Simons et al. (2004) concluded that not only the dynamic aspects of FTP but also its cognitive aspect plays an important role in understanding the positive motivational effects of FTP. Simons et al. (2004) also defined different types of instrumentality such as low utility-external regulation where the individual is only driven by extrinsic reasons; low utility-internal regulation where the activity is internally regulated but there is no relationship between the present and future task; high utility-external regulation where one strives for future goals but the reasons are extrinsic; and high utility-internal regulation where one strives for future goals that internally regulate the present actions. Furthermore, Simons, Dewite, and Lens (2004) recently showed that when PI is internally regulated, students were more task oriented, more excited about the course, used more deep level strategies, persisted more, and performed better (as measured by examination scores). Zimbardo and Boyd (1999) demonstrated that FTP, as one of the subscales of the Time Perspective Inventory, was positively correlated with undergraduate students' GPA. Recently, Malka and Covington (2005) examined the perceptions among university students that school performance is instrumental to future goal attainment. As a result, they found that not FTP-valance, but FTPconnectedness and PI significantly predicted students' GP. They also found that the interaction between connectedness and valance significantly predicted students' GP. More recently, Shell and Husman (2008) examined the relationships among undergraduate students' selfreported control, goal orientation, FTP, affect, and strategic self-regulation. Of particular importance, they found that FTP-connectedness was not correlated with undergraduate students' grade outcome expectancy regarding educational psychology course whereas FTP-value was weakly and positively correlated with their grade outcome expectancy, representing that the relationships among FTP-valance, FTP-connectedness, and academic achievement were not warranted when academic achievement was conceptualized within a single course. 
Adelabu (2007) demonstrated that FTP is a significant and positive predictor of academic achievement among African American female adolescents, but not among male adolescents. Specifically, female adolescents' FTP positively correlated with academic achievement whereas male adolescents' present time perspective negatively correlated with academic achievement. Although the studies that focused on gender differences in FTP have revealed somewhat mixed results (Greene \& DeBacker, 2004), Adelabu's (2007) study suggests that gender effects on FTP should also be considered when the relationship between academic achievement and FTP are examined. Similarly, a recent research by Padawer et al. (2007) revealed that gender, as well as age, is a significant predictor of FTP. Specifically, longer future orientations were found among four types of individuals: those who were older, more highly educated, male, and had higher incomes (Padawer et al., 2007). In summary, both Adelabu (2007) and Padawer et al. (2007) studies suggest that gender variable should be considered in a study through which individuals' FTP was examined. Thus, gender variable was controlled as a background variable in the analyses. However, it was not discussed because gender was not a variable of interest in this study.

In the light of the studies reviewed above, it can be argued that FTP and PI are important variables that are used to explain student motivation and academic achievement. It can also be suggested that demographic variables such as culture, social class, age, and gender all contribute in the relations between students' FTP, PI, and GP. However, to the best of the researcher's knowledge, there is no such study in which the relationships among these variables have been examined through a longitudinal study. Thus, a longitudinal design was adopted in the present study in order to examine the possible changes in students' FTP and PI with a robust approach (Fraenkel \& Wallen, 2006). However, based on the fact that this was a 14week research project (see period and course content section below), it is more appropriate to refer to the mentioned design as a short-term longitudinal design.

\section{Aims and Research Questions}

This study has two aims: First, it is to explore the possible changes in FTP and PI over a period as long as one academic semester; and second, it is to explore whether the changes in FTP and PI, if any, explain students' GP with regard to a specific course; educational psychology. In line with these aims, two research questions were formulated: (a) do students' FTP-value, FTP-connectedness, and PI at T2 significantly differ from their FTP-value, FTP- 
connectedness, and PI at T1?; (b) can the students' GP be explained by those changes in their FTP-value, FTP-connectedness, and PI?

As mentioned earlier, previous research revealed that younger people are more futureoriented than older people (e.g., Cate \& John, 2007; Lang \& Carstensen, 2002), indicating that individuals' FTP is not fixed, but malleable by nature. On the other hand, it has long been known that experiences in general and educational experiences in particular are effective in shaping individuals' FTP and PI (e.g., Gjesme, 1983; Zimbardo \& Boyd, 2008). Thus, it is not entirely speculative to predict that the undergraduate students' FTP and PI may change over one academic semester due to the effect of their educational experiences on their FTP and PI. Finally, the well-evidenced effects of FTP and PI on GP (e.g., Malka \& Covington, 2005) may encourage one to hypothesize that those possible changes in undergraduate students' FTP and PI may significantly affect GP.

\section{Method}

\section{Participants}

A total of 201 first year undergraduate students taking educational psychology course voluntarily participated in the study. Of them, 13 were excluded from the analyses due to missing data and non-attendance. Therefore, the sample of this study consisted of 188 firstyear undergraduate students (45 females and 143 males) majoring in Classroom Teaching (n =71), English Language Teaching $(n=60)$, and Art Teaching $(n=57)$ in a large university located in the North-West of the Black Sea Region in Turkey. Participants ranged in age from 18 to 26 years old $(\mathrm{M}=19.36, \mathrm{SD}=1.34)$. In Turkey, like in other countries, the cost of university education is relatively high for undergraduate students. Thus, it was assumed that the level of the sample students' Socio Economic Status (SES) was at least medium.

\section{Research Instruments}

\section{The Turkish Version of the Future Time Perspective Scale}

The Turkish Version of the Future Time Perspective Scale (TVFTPS) (Eren, 2007), originally developed by Husman and Shell (2008), was used to assess students' FTP. The TVFTPS, which is a five-point likert type scale ranging from 5 (strongly agree) to 1 (strongly disagree), has two factors such as connectedness (e.g., It's not really important to have future 
goals for where one wants to be in five or ten years - reverse coded) and value (e.g., What happens in the long run is more important than how one feels right now).

Using the Maximum Likelihood (ML) method from STATISTICA 7 [StatSoft Inc., Tulsa, OK, 2004], Confirmatory Factor Analysis (CFA) was conducted in order to examine the factor structure of the TVFTPS. Because $\chi^{2}$ measure is sensitive to sample size, $\chi^{2} / \mathrm{df}$ ratio $\left(\chi^{2} / \mathrm{df} \leq 3\right)$, Root MSE of Approximation (RMSEA $\left.\leq .08\right)$, Adjusted Goodness of Fit Index (AGFI $\geq .90)$, Goodness of Fit Index (GFI $\geq .90)$, and Comparative Fit Index (CFI $\geq .90)$ were used to assess data fit. The CFA results demonstrated that the two-factor model with 14 indicators had acceptable fit to data $\left(\chi^{2}(76)=126.95 ; \chi^{2} / \mathrm{df}=1.67 ; \mathrm{RMSEA}=.058 ; \mathrm{GFI}=91\right.$; $\mathrm{AGFI}=.89$; CFI $=.89$ ), signifying that the factor structure of the TVFTPS was confirmed in the present study. With considerable loadings ranging from .62 to .73, all items in the scale significantly linked to their related factors. Finally, the relationship between FTP-value and FTP-connectedness were .51, indicating that these factors were related, but independent factors.

\section{The Perceived Instrumentality Scale}

The Perceived Instrumentality Scale (PIS) (Miller et al., 1999), which has widely been used in the relevant research (e.g., Malka \& Covington, 2005; Miller et al., 1999), was used to assess students' PI with respect to the educational psychology course. The PIS, which is also a five-point Likert type scale, ranging from 5 (strongly agree) to 1 (strongly disagree), has five items (e.g., I do the work assigned in this class because my achievement plays a role in reaching my future goals) with possible scores ranging from 5 to 25 . Because one-factor with five indicators may seriously limit the degrees of freedom, not the ML method, but the Ordinary Least Squares (OLS) method was used in CFA. Unfortunately, OLS method does not report RMSEA and $\chi^{2}$ measures. Thus, in addition to the GFI, AGFI, and CFI, Normed Fit Index $(\mathrm{NFI} \geq .90)$ was used to assess data fit. Results showed that the one-factor model with five indicators had good fit to data $(\mathrm{NFI}=.98 ; \mathrm{GFI}=.99 ; \mathrm{AGFI}=.97 ; \mathrm{CFI}=.99)($ Bollen $\&$ Curran, 2006). 


\section{Period and Course Content}

One semester is equal to 14 weeks in the university where the present study was carried out. Students' FTP and PI were measured both at the beginning (T1) and at the end of the academic semester (T2). Furthermore, each educational psychology course was given by the different lecturers ( 1 woman and 2 men) that they differed in their approaches to teaching. Specifically, one of the lecturers (henceforth called LA) tended to use more traditional or teacher-centred approaches to teaching such as lecturing whereas two of them (henceforth called LB and LC) tended to use more student-centred approaches to teaching such as discussion based seminars (personal communication with lecturers). Given the well-evidenced positive effects of student-centred approaches on student achievement (e.g., Ramsden, 1993; Yorke \& Longden, 2004), the lecturer effect on GP was also taken into account in the present study in order to control its possible effects. The means of the lecturers' age and year of experience were $42.00(\mathrm{SD}=4.36)$ and $12.67(\mathrm{SD}=5.51)$ respectively. Finally, the syllabus of the educational psychology course contains common topics such as child development, motivation, and learning in each fields of study.

\section{Graded Performance}

In the present study, GP was equal to students' performance in educational psychology course. Officially, GP in one course is sum of the scores of at least one midterm exam (weighted as $40 \%$ ) and one final exam (weighted as $60 \%$ ) due to the written regulations of the university where the present study was carried out. Each lecturer verbally reported that they carried out one midterm examination and one final examination in order to assess their students' performance in the educational psychology course. Thus, the GP was represented with the sum of these scores so that the higher the score the higher the GP $(\mathrm{M}=66.79 ; \mathrm{SD}=$ 16.50). These scores were requested from the lecturers at the end of the academic semester.

\section{Procedure}

Data were obtained during the spring semester of the 2007-2008 academic year. The TVFTPS and PI were applied both at T1 and T2 with a few day intervals in order to prevent a possible response bias. The scales were presented to participants with instructions concerning the aim of the study and brief explanations about the constructs. These instructions were also read aloud at the beginning of the process, and any questions from the participants were answered. Demographics (i.e., gender, age - reported as open ended) were assessed by selfreport on the scales. 


\section{Analyses}

Before addressing the research questions, Exploratory Factor analysis (EFA) (cut off .30) was conducted in order to examine the factor stability of the TVFTPS and PIS. In the EFA, the ML method with promax rotation was used in order to control the relationships among the factors of the scales. For the first research question, both Pearson product-moment correlation and paired-samples t test analyses were conducted. Cohen's $d$ coefficients were also calculated in order to see the effect sizes of the mean-level changes in FTP and PI (Cohen, 1977). These measures have typically been used to assess the mean-level change within a sample (Pagano, 2007). However, Fryer and Elliot (2007) demonstrated that focusing on a mean level change in a longitudinal study may mask the individual-level change. In other words, the absence of mean-level change for a particular construct at the sample level may be due to an increase for a sizable number of individuals cancels out the decrease for a comparable number of persons (Fryer \& Elliot, 2007).

For this reason, following Fryer and Elliot (2007) the Reliable Change Index (RCI) was used to investigate person-level change in addition to mean-level change (see Jacobson \& Truax, 1991 for a broader explanation). RCI was measured by "dividing the difference in T1 and T2 scores by the standart error of the difference score" (Fryer \& Elliot, 2007, p. 702). Additionally, "based on the values smaller than -1.96 or larger than 1.96 , which are unlikely to occur by chance and are thus considered indicative of reliable change, RCI allows individuals to be categorized as showing a significant decrease, a significant increase, and nochange" (Fryer \& Elliot, 2007, p. 702). Thus, based on the categories of significant increase and significant decrease, the RCI-increase and RCI-decrease scores were created for FTPvalue, FTP-connectedness, and PI. Accordingly, the RCI-increase scores were created by setting the RCI-decrease scores to zero for each variable (i.e., FTP-value, FTP-connectedness, and PI) whereas the opposite procedure was applied to RCI-decrease scores. For example, the scores of increase in FTP-value were created by setting the scores of those students who were in the FTP-decrease and no-change categories to zero. By so doing, it was aimed to obtain the clear increase and decrease scores with regard to the categories of RCI. However, the nochange categories were not considered due to the small number of students in each category.

Hierarchical Regression Analysis (HRA) was conducted to examine whether students' GP with regard to the educational psychology course can be explained by those changes in 
FTP-value, FTP-connectedness, and PI (Weinberg \& Abramowitz, 2002). In addition to age and gender, lecturer variable (LA was determined as an outer category) was also considered in HRA to control its possible effect on GP. Although one can argue that the domain effect on dependents may interfere with the lecturer effect because the sample students in each fields of study take educational psychology course from different lecturers, it can be said that the domain effect on GP, if any, tends to be smaller than the lecturer effect on GP due to the fact that sample students were all first-year undergraduate students. Accordingly, it is more reasonable to expect a lecturer effect on GP than to expect a domain effect on GP. Thus, not the fields of study, but the lecturer variable was subjected to HRA. Age, gender, and lecturer variables were entered in the first step of the analyses. In the second step, the scores of increase in FTP-value (RCIVI), FTP-connectedness (RCICI), and PI (RCIPI) were entered into the regression equation. The scores of decrease in FTP-value (RCIVD), FTP-connectedness (RCICD), and PI (RCIPD) were entered in the third step of the analyses. The interactions among those variables of RCI-decrease, RCI-increase, and lecturer (a total of 12 sets were determined), as well as the interactions among those scores of changes in FTP-connectedness, FTP-value, and PI (a total of 4 sets were determined), were also controlled in the HRA.

Finally, based on the results of the HRA, a structural model was created in order to examine the mediating role of the lecturer variable in relationship between GP and the increase and decrease scores of FTP and PI (Ullman, 2007). Using Structural Equation Modeling (SEM) approach, the hypothesized structural model was tested in terms of fit indices (i.e., $\chi^{2} / \mathrm{df}$ ratio, GFI, AGFI, CFI, RMSEA). In the model, there were two latent variables: One was represtented with the FTP and PI increase variables (i.e., RCIVI, RCICI, and RCIPI) whereas the other represented with the FTP and PI decrease variables (i.e., RCIVD, RCICD, and RCIPD). The lecturer and GPA scores were included as observed variables in the model. 


\section{Results}

\section{Preliminary analysis}

Both initial (T1) and final (T2) scores of FTP-value, FTP-connectedness, and PIS were included in the EFA. As a result, scree-plot revealed that the six-factor solution was more appropriate than other number of factor solutions. Thus, six-factor solution was applied to data. The factor loadings, Eigen values, and the proportions of the explained total variance were presented in Table 1.

Table 1. Factor loadings at Time 1 and Time 2

\begin{tabular}{|c|c|c|c|c|c|c|}
\hline \multirow{4}{*}{$\begin{array}{l} \\
\text { Item number } \\
\text { Value }\end{array}$} & \multicolumn{6}{|c|}{ Factors } \\
\hline & \multicolumn{3}{|c|}{ Time 1} & \multicolumn{3}{|c|}{ Time 2} \\
\hline & 1 & 2 & 3 & 1 & 2 & 3 \\
\hline & \multicolumn{6}{|c|}{ Value } \\
\hline 1 & .329 & & & .638 & & \\
\hline 2 & .357 & & & .645 & & \\
\hline 3 & .422 & & & .646 & & \\
\hline 4 & .491 & & & .648 & & \\
\hline 5 & .503 & & & .741 & & \\
\hline 6 & .571 & & & .741 & & \\
\hline 7 & .591 & & & .742 & & \\
\hline \multicolumn{7}{|l|}{ Connectedness } \\
\hline 1 & & .352 & & & .492 & \\
\hline 2 & & .409 & & & .545 & \\
\hline 3 & & .425 & & & .551 & \\
\hline 4 & & .534 & & & .648 & \\
\hline 5 & & .610 & & & .763 & \\
\hline 6 & & .653 & & & .805 & \\
\hline 7 & & .757 & & & .898 & \\
\hline \multicolumn{7}{|l|}{ Perceived Instrumentality } \\
\hline 1 & & & .646 & & & .741 \\
\hline 2 & & & .673 & & & .769 \\
\hline 3 & & & .792 & & & .787 \\
\hline 4 & & & .794 & & & .892 \\
\hline 5 & & & .839 & & & .924 \\
\hline Eigen values & 1.14 & 1.57 & 2.27 & 2.07 & 7.01 & 3.44 \\
\hline Explained variance $(\%)$ & 3.01 & 4.14 & 5.97 & 5.46 & 18.45 & 9.04 \\
\hline Explained total variance $(\%)$ & & & & & & \\
\hline
\end{tabular}

Note. Only loadings over .30 were presented. No cross-loadings among the items of factors were observed.

As seen in Table 1, for the FTP-connectedness dimension, factor loadings ranged from .352 to .757 at T1 whereas they ranged from .492 to .898 at T2. For the FTP-value dimension, factor loadings ranged from .329 to .591 at $\mathrm{T} 1$ whereas they ranged from .638 to .742 at $\mathrm{T} 2$. 
Finally, for the PIS, factor loadings ranged from .646 to .839 at T1 whereas they ranged from .741 to .924 . Importantly, as seen in Table 1, all Eigen values were greater than 1 (Kaiser, 1960). These results indicate that the factors of the scales remained quite stable during the semester. Thus, it can be said that the results of the EFA pointed out that those possible changes in undergraduate students' FTP and PI can not be attributed to the artificial effects of the factor instability on FTP and PI (Tabachnick \& Fidell, 2007).

Changes in Future Time Perspective and Perceived Instrumentality

Zero-order correlations were presented in Table 2.

Table 2. Zero-order correlations

\begin{tabular}{|c|c|c|c|}
\hline Variable & 1 & 2 & 3 \\
\hline (1) Value & -.11 & $.37 * *$ & $.21 * *$ \\
\hline (2) Connectedness & $.46^{* *}$ & .01 & $.28 * *$ \\
\hline (3) Perceived Instrumentality & $.40 * *$ & $.49 * *$ & -.05 \\
\hline
\end{tabular}

As seen in Table 2, FTP-value, FTP-connectedness, and PI were moderately correlated with one another at both $\mathrm{T} 1$ and $\mathrm{T} 2$, indicating that they were related, but distinct dimensions. However, none of them were correlated with their counterparts at T2. More specifically, neither the relationship between FTP-value at T1 and FTP-value at T2 nor the relationship between FTP-connectedness at T1 and FTP-connectedness at T2 was significant ( $>$ >.05). Moreover, these correlations were extremely weak. The same was also true for the relationship between PI at T1 and PI at T2 (see Table 2). The results of the paired samples t-test analysis were shown in Table 3. 
Table 3. The summary of the paired samples t-test results

\begin{tabular}{|c|c|c|c|c|c|c|}
\hline \multirow[b]{2}{*}{ Variable } & \multicolumn{2}{|c|}{ Time 1} & \multicolumn{2}{|c|}{ Time 2} & \multirow[b]{2}{*}{$t$} & \multirow[b]{2}{*}{$d$} \\
\hline & M & SD & M & SD & & \\
\hline Value & 24.30 & 4.93 & 25.82 & 5.37 & $-2.71 * *$ & .30 \\
\hline Connectedness & 27.34 & 4.77 & 28.49 & 4.70 & $-2.36^{*}$ & .24 \\
\hline Perceived Instrumentality & 20.16 & 3.80 & 20.74 & 3.38 & -1.52 & .08 \\
\hline
\end{tabular}

As displayed in Table 3, FTP-value and FTP-connectedness at T2 significantly differed from their counterparts at T1. Although the effect sizes were small, it can be said that those changes in FTP-valance and FTP-connectedness over the semester were not negligible. Students' PI, on the other hand, did not significantly change from T1 to T2. Indeed, the effect size was trivial for the mean-level change in PI (see Table 3). As emphasized earlier, focusing on a mean-level change in a longitudinal study may mask the individual or person-level change. Therefore, reliable changes were computed to examine the person-level changes in FTP-value, FTP-connectedness, and PI (see Table 4).

Table 4. The reliable changes in future time perspective and perceived instrumentality

\begin{tabular}{lcccc}
\hline Variable & Increase(\%) & No-change(\%) & Decrease(\%) & $\chi^{\mathbf{2}}(\mathbf{2})$ \\
\hline Value & 51.1 & 15.4 & 33.5 & $154.77^{* * *}$ \\
Connectedness & 53.2 & 6.9 & 39.9 & $147.34^{* * * *}$ \\
Perceived Instrumentality & 44.1 & 15.4 & 40.5 & $159.14^{* * *}$ \\
\hline$\quad * * *$ p $<.001$ & & & &
\end{tabular}

The RCI analysis demonstrated that sample students' FTP-connectedness, FTP-value, and PI were reliably changed over the semester (see Table 4). Although it was represented with relatively small proportions, stability was also the case in students' FTP and PI, indicating that both change and stability in students' FTP and PI may simultaneously emerge within a sample. More specifically, of them, $51.1 \%$ were reliably and significantly increased in FTPvalue whereas $33.5 \%$ were reliably and significantly decreased in FTP-value. Similarly, of them, $53.2 \%$ were increased in FTP-connectedness whereas $39.9 \%$ were decreased in FTP- 
connectedness. Of them, $44.1 \%$ were increased in PI whereas $40.5 \%$ were decreased in PI. In addition, those proportions of stability in students' FTP-value, FTP-connectedness, and PI were $15.4 \%, 6.9 \%$, and $15.4 \%$ respectively. In sum, it can be said that RCI analysis replicated those results of the paired sample t-tests. However, RCI results for PI-change were somewhat different from the t-test results (see Table 3 and Table 4), signifying that PIincrease and PI-decrease cancelled each other due to the proximity in the proportions of PIdecrease (40.5\%) and PI-increase (44.1\%), which, in turn, may overshadow those mean-level changes in PI.

Graded Performance as a Function of the Changes in Future Time Perspective and Perceived Instrumentality

The results of the HRA analysis were summarized in Table 5.

Table 5. The summary of the hierarchical regression results

\begin{tabular}{llcccc}
\hline Variable & & \multicolumn{3}{c}{} & \\
\hline Step 1 & Age & $\mathrm{B}$ & $\mathrm{S}$. Error & $\beta$ & $\mathrm{p}$ \\
& Gender & -.15 & .69 & -.01 & .833 \\
& LB & 1.92 & 2.11 & .05 & .364 \\
& LC & 26.44 & 3.55 & $.78^{* * *}$ & .000 \\
& Model Summary & 20.16 & 3.88 & $.57^{* * *}$ & .000 \\
Step 2 & Age & $\mathrm{R}^{2}=.58 ; \Delta \mathrm{R}^{2}=.17 ; \mathrm{F}(20,167)=11.58, \mathrm{p}<.001$ \\
& Gender & -.17 & .70 & -.01 & .808 \\
& LB & 1.78 & 2.15 & .05 & .409 \\
& LC & 25.60 & 3.78 & $.75^{* * *}$ & .000 \\
& RCIVI & 19.14 & 4.09 & $.54^{* * *}$ & .000 \\
& RCICI & .23 & .21 & .12 & .261 \\
& RCIPI & -.12 & .24 & -.07 & .606 \\
& Model Summary & .03 & .18 & .02 & .870 \\
Step 3 & Age & $\mathrm{R}^{2}=.58 ; \Delta \mathrm{R}^{2}=.00 ; \mathrm{F}(23,164)=10.03, \mathrm{p}<.001$ \\
& Gender & -.23 & .70 & -.02 & .742 \\
& LB & 1.10 & 2.15 & .05 & .353 \\
& LC & 31.13 & 4.87 & $.92^{* * *}$ & .000 \\
& RCIVI & 24.59 & 5.04 & $.70^{* * *}$ & .000 \\
& RCICI & -.00 & .25 & .00 & .992 \\
& RCIPI & -.34 & .27 & .18 & .206 \\
& RCIVD & -.07 & .20 & .04 & .723 \\
RCICD & .49 & .31 & -.22 & .118 \\
RCIPD & .17 & .24 & -.08 & .475 \\
Model Summary & .18 & .26 & -.08 & .491 \\
\hline
\end{tabular}

$* * * \mathrm{p}<.001$

Note. LB: Lecturer B; LC: lecturer C; RCIVI: increase in FTP-value; RCICI: increase in FTP-connectedness; RCIPI: increase in perceived instrumentality; RCIVD: decrease in FTP-value; RCICD: decrease in FTP-connectedness; RCIPD: decrease in perceived instrumentality. The interactions were also checked out, but not shown in the Table. 
As shown in Table 5, there was a significant lecturer effect on students' GP, which was explained the considerable amount of the model $\left(\mathrm{R}^{2}=.59\right)$, indicating that the LB $(\beta=$ $.92, p<.001)$ and LC $(\beta=.70, p<.001)$, compared to LA, significantly and positively affected students' GP with regard to the educational psychology course. As a matter of fact, lecturer effect on GP remained significant in each step of the analyses whereas the effects of age and gender were insignificant and trivial (see Table 5).

Those effects of increases in FTP-value $(\beta=.00, n s)$, FTP-connectedness $(\beta=.18, n s)$, and PI $(\beta=.04, n s)$ on GP were found to be insignificant. The same was also true for those effects of decreases in FTP-value $(\beta=-.22, n s)$, FTP-connectedness $(\beta=-.08, n s)$, and PI $(\beta=$ $-.08, n s)$ on GP. To sum up, HRA results showed that the lecturer variable both uniquely and considerably explained the variance in GP $\left(\mathrm{R}^{2}=.59\right)$. Based on the results of the HRA (see Table 5), it can be said that the effects of changes in FTP and PI on GP may be suppressed by the effects of the lecturer variable on GP, suggesting a mediating role for the lecturer variable in relationship between GP and increase and decrease scores of FTP and PI. Thus, a structural model was created in order to test this claim. The relationships among the variables of FTP/PI-increase, FTP/PI-decrease, lecturer, and GP were presented in Figure 1.

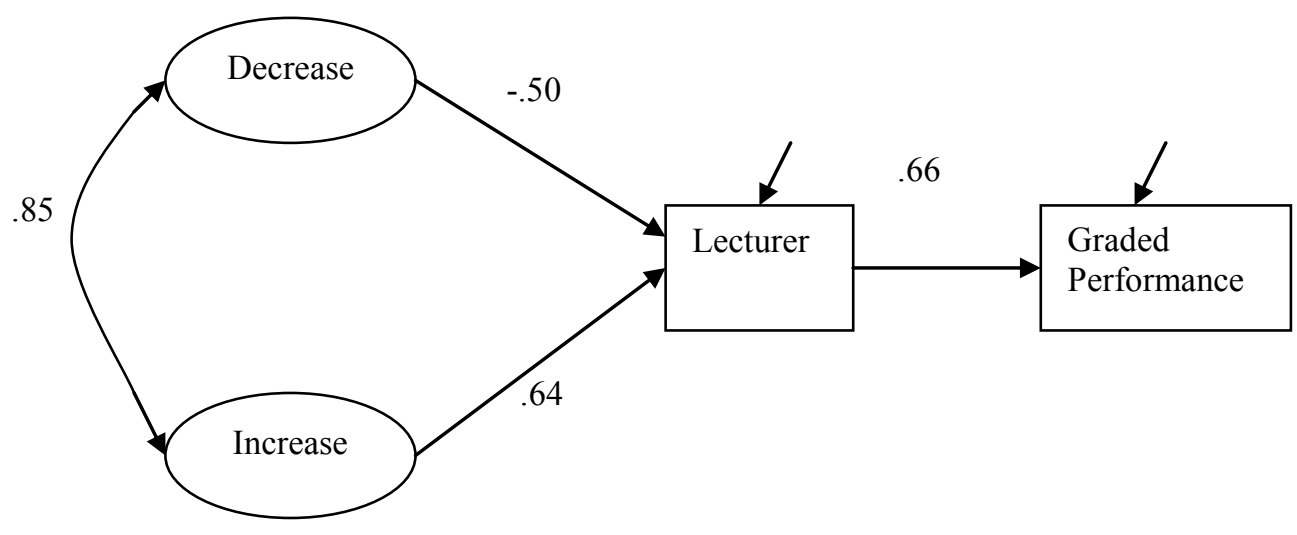

Figure 1. The mediating role of the lecturer variable

Note. The manifest variables and standard errors were not shown for the sake of clarity and simplicity.

As shown in Figure 1, both increase (i.e., FTP and PI-increase) and decrease (i.e., FTP and PI-decrease) variables considerably predicted the lecturer variable, which, in turn, predicted GP. However, the structural model marginally fitted to the data $\left(\chi^{2}(18)=53.06 ; \chi^{2} / \mathrm{df}=\right.$ 
2.95; $\mathrm{RMSEA}=.10 ; \mathrm{GFI}=.94 ; \mathrm{AGFI}=.87 ; \mathrm{CFI}=.88)$, indicating that the mediating role of the lecturer variable in relationship between GP and increase/decrease scores of the FTP and PI was weakly supported.

\section{Discussion}

As predicted, the results of both mean-level change analysis and person-level change analysis showed that FTP-connectedness and FTP-value, and PIS significantly changed over a short period of time such as one academic semester. Furthermore, results of the preliminary analysis revealed that the mentioned changes in undergraduate students' FTP and PIS were not due to the instability of the factors in the scales. Although the previous studies demonstrated that FTP is malleable by nature (e.g., Cate \& John, 2007; Lang \& Carstensen, 2002), none of them were comparable with the present study because they focused on FTP-change as a function of the individuals' age, which was not the case in the present sudy. Thus, the result of the present study has broadened our current understanding regarding the malleable nature of FTP in three ways: Firstly, previous research did not show that those changes in FTP-value and FTP-connectedness may emerge over a short period of time as long as one academic semester. Secondly, as revealed through person-level analysis, the changes in students' FTP and PI were not one-sided, but double-sided such as "decrease" and "increase". Thirdly, and more importantly, as also demonstrated through person-level analysis, some students' FTP remained stable over the semester.

Taken all together, the results of the mean-level change analysis provide an additional evidence regarding the malleable nature of FTP whereas, moving one step further, the results of the person-level change analysis, which were mainly consistent with the results of the mean-level change analysis, revealed that both the malleability and the stability in students' FTP and PI may emerge in educational settings such as university. At this point, a question arises: why some students' FTP and PI demonstrated a change while others' FTP and PI remained stable.

A possible explanation can be provided based on both the control beliefs, concerning the extent to which persons believe they can control or influence their environment to attain desired outcomes (Shell \& Husman, 2001, 2008) and achievement-related personal goals, 
concerning the purposes or goal orientations that students construe for action in achievementrelated settings such as school (Levy-Tossman, Kaplan, \& Assor, 2007). Although these variables were not examined in the present study, there is evidence that control beliefs and achievement goals are somewhat related with FTP (e.g., Shell \& Husman, 2001). Specifically, the higher the students' control beliefs about the achievement-related tasks, the higher they focused on the future consequences of their current behaviors regarding these tasks, and the higher they valued these achievement-related behaviors (Shell \& Husman, 2001). If this is the case, it is reasonable to speculate that the undergraduate students' beliefs about the degree to which they control or manipulate their environment in the educational psychology class may mediate the relationship between the initial and final view of their FTP and PI. Indeed, it has long been acknowledged that students' control beliefs are, at least partly, shaped by their past educational/instructional experiences, which, in turn, may explain why some students' FTP and PI demonstrated a change while others' FTP and PI remained stable (see, for example, Bandura, 1997).

For example, some students may increase their FTP and PI due to the positive experiences they held in educational psychology class during the semester (e.g., midterm exam results, lecturer-student interaction, and peer-relations), whereas some students may decrease their FTP and PI due to the negative experiences they held in the same class. Following the same reasoning, it is reasonable to claim that some students' FTP and PI remained stable due to the possible effects of their own class-related experiences on control beliefs were not strong enough to change the initial view of their FTP and PI. Given that the participants in the present study were student teachers, the subjective experiences they held in pedagogy classes such as educational psychology are crucial because of the nature of the roles that these students are expected to adopt in the future as a "teacher". It is obvious that such kind of roles requires them to link their current behaviors to future goals as tightly as possible in order to become a succesful teacher, which, in turn, make them more sensible to the effects of these class-related experiences they held in pedagogy classes such as educational psychology (Slavin, 2003). If this is the case, this may explain why a considerable number of student teachers changed their FTP and PI, whereas a small amount of student teachers' FTP and PI remained stable during the semester. However, as noted earlier, because both personal goals and control beliefs were not considered in the present study, these explanations remained somewhat speculative. Therefore, these claims deserve further investigation. 
In contrast to the expectation, the HRA results showed that the changes in students' FTP and PI did not explain their GP with regard to the educational psychology course. This may be due to the fact that the temporal range was not long enough to reveal the possible effects of FTP and PI on GP, although it was enough to reveal the significant changes in FTP and PI. Obviously, this issue needs further investigation. The HRA results also demonstrated that the lecturer effect was explained more than half of the variance in students' GP, pointing out that GP can not be explained by the changes in FTP and PI, but by the lecturer effect on GP. As emphasized earlier, lecturer B and lecturer C, compared to lecturer A, used more student-centred approaches to teaching, which, in turn, may cause a significant lecturer effect on GP (Farris, 1996; Ramsden, 1993; Yorke \& Longden, 2004). Moreover, none of the interactions among lecturer, FTP-decrease, FTP-increase, PI-increase, and PI-decrease were found to be significant, suggesting that the lecturers effect on GP were not originated from the interactions among the variables at hand.

Interestingly, the effects of the interactions among changes in FTP-value, FTPconnectedness, and PI on GP did also not reach a significant level, which was also not in line with the previous research (DeVolder \& Lens, 1982; Malka \& Covington, 2005). This may be due to the fact that not the direct measures of reliable changes in FTP and PI, but the crosssectional effects on GP were examined in previous studies. Thus, it can be said that this result is not comparable with the results of the previous studies because not the cross-sectional effects, but the reliable change effects on GP were considered in the present study. Nevertheless, given that the PI is a task-specific counterpart of the FTP (Gjesme, 1983), it is hard to understand why those changes in PI did not affect GP, which is more expectable than the FTP effects on GP due to the course or task-specific nature of the PI (Malka \& Covington, 2005). At this point, it can be speculated that the PI was a necessary, but not a sufficient condition to affect students' GP. Likewise, Creten, Lens, and Simons (2001) found that recognizing the utility of a course (i.e., French) was not sufficient to enhance the motivation to study that course. Similarly, Van Calster, Lens, and Nuttin (1987) also showed that high PI combined with a positive attitude toward the future gave the highest motivation to study and the best academic performance. Taken all together, these studies (Creten et al., 2001; Van Calster, 1987) pointed out that not only the PI, but positive attitudes toward the future should be considered in order to strengthen the effects of those changes in PI on GP. It is worth noting that these speculations need further investigation because undergraduate students' motivation was not measured in the present study. 
The SEM results, on the other hand, provided an alternative explanation regarding the effects of those increase and decrease scores of FTP and PI on GP. Accordingly, the relationship between undergraduate students' GP and the increase and decrease scores of FTP and PI was mediated by the lecturers. This means that the lecturers played a crucial role in reflecting the effects of those changes in students' FTP and PI on GP in educational psychology class. Seemingly, the effects of those increase and decrease scores of FTP and PI were somehow filtered by the lecturers. At this point, it can be speculated that the lecturers' perceptions, beliefs, and/or attitudes about their students' future or goal-related behaviors may filter the effects of those increase and decrease in FTP and PI on GP. Although the hypothesized structural model marginally fit to the data, it deserves a further investigation. In fact, this marginality can be due to the small sample size (Ullman, 2007).

Finally, HRA results demonstrated that gender and age did not significantly affect students' GP. Based on the recent research (Adelabu, 2007; see also Greene \& DeBacker, 2004), it can be said that the gender effect on GP is not the function of the direct relationship between GP and gender variable. Rather, some important variables such as students' cultural backgrounds may relate to gender, which, in turn, may differentiate the relationship between gender and GP. Indeed, recent evidence suggests that an individual's gender can not solely be explained by its biological origins, but also by its socio-cultural origins (see, for example, Seginer \& Mahajna, 2004) which are more evident in educational settings (see Moé \& Pazzaglia, 2006 for some recent evidence about how these gender-stereotypes are effective on academic achievement). Therefore, cultural background and gender interaction may play an important role in academic achievement and/or GP, which needs also further investigation to shed light on those mixed results regarding the relationship between academic achievement and gender (Greene \& DeBacker, 2004).

\section{Implications for Education}

The results of the present study showed that FTP and PI significantly and reliably changed over one academic semester. If malleability in FTP and PI reveals itself over a short period of time such as one academic semester, which means that they are more open to the effects of educational environment than it has been assumed to date, then instructors/teachers may adopt some approaches even for over a short period of time to alter their students' FTP and PI in an adaptive way. For example, "students are most likely to perform better when it is 
explained to them that their behavior yields important future benefits, and when this message is conveyed in an autonomy-supportive fashion" (Simons et al., 2004, p. 133). However, in terms of Simons et al. (2004, p. 133) "teachers and instructors vaguely point out to the future importance of students' present behavior only by briefly mentioning that the present activity will crucially affect their future". Although it is not known whether or not the same is also true for the students in this sample, the results of the regression analysis showed that there was no interaction between the lecturer and the changes in students' FTP and PI, suggesting that those changes in students' FTP and PI were independent from the effects of lecturer.

Therefore, it can be said that the future importance of students' present behavior, as well as the future importance of a specific course, should clearly be stated in educational settings such as university (Simons et al., 2004). For instance, to give clear and striking examples about real life situations that require students to focus on their present behavior for the sake of their future may be beneficial for bridging the gap between their present steps and their future. In addition, inviting real life models to the classroom, who are successful in their career which the students are studying and striving for, may also be a fruitful approach to arouse awareness as to the intertwined nature of the relationship between the present and the future (Creten et al., 2001).

The results of this study also showed that neither the increase in FTP nor the increase in PI significantly affected GP. As discussed above, one of the main reasons for this result was that PI was a necessary, but not a sufficient condition to enhance students' motivation to study (Creten et al., 2001), suggesting that not only PI, but other variables such as positive attitudes toward the future (Van Calster et al., 1987) should be considered in educational settings. In other words, based on both the result of this study and the relevant literature, it can be suggested that students' PI should be considered together with the other important futurerelated variables one of which can be positive attitudes toward future in order to enhance student motivation and academic achievement. More specifically, because induction of a FTP in present activities will "increase the motivation only for students with a positive attitude toward the future" (Van Calster et al., 1987, p. 10), teachers and instructors should focus on both students' positive attitudes towards the future and PI in order to enhance the effects of positive changes in FTP and PI on GP or overall academic achievement in educational settings. Finally, results of the present study revealed that the effects of those decrease and increase in undergraduate students' FTP and PI on GP were somewhat mediated by the lectur- 
ers. This means that teachers and instructors should not only focus on their students' attitudes towards the future, but also focus on their own attitudes, beliefs, and/or perceptions about the future in order to recognize their roles in reflecting the effects of those changes in students' FTP and PI on GP.

\section{Directions for Future Research}

The results of the present study demonstrated that both stability and change in FTP and PI may be observed over a short period of time in educational settings such as university. However, because this study was an initial step, similar studies are needed to confirm the current results. In addition, possible domain effects on GP were not taken into account in the present study. However, future research, in which the lecturer and the domain effects as well as the interaction between them would also be considered, may provide a broader picture about the effects of educational environment on students' academic achievement. On the other hand, the results of this study showed that neither FTP-decrease/increase nor PIdecrease/increase affected students' GP. As discussed earlier, this may be due to the fact that GP was considered as a function of one specific course. Therefore, GP should be more broadly defined such as overall academic achievement in future research. It will also be interesting to see whether the possible changes in other variables such as attitudes toward future, control beliefs, and achievement goals, each of which were found to be related with the FTP and PI in previous research (Van Calster et al., 1987; Shell \& Husman, 2001), contribute to student motivation and achievement.

Finally, the lecturers' teaching approaches were determined based on personal communication with them. Although this method was effective in understanding the lecturers' teaching approaches in the present study, more valid and reliable methods such as observation and/or interviews should be used in future research in order to obtain more comprehensive an robust data regarding the lecturers teaching approaches to teaching.

\section{Limitations}

This study has several limitations. First, the sample size was relatively small which has limited the generalizability of the current results. Second, self-report measures were used to assess students' FTP and PI. Despite the fact that their psychometric properties were found to be satisfactory, both the TVFTPS and the PIS limited the sample students' perceptions due to their own structures. For example, students' PI could have been investigated through the 
four-factor structure as Simons et al. (2004) recently did. However, because this study was an initial step, PI was treated as a unitary and externally-regulated construct in order to simplify and clarify the results of those possible changes in students' PI. Third, the data were obtained from only one university. Although the university, where the present study was carried out, was highly representative of the Turkish Higher Educational System, this may also be viewed as a limitation. Finally, the present study was a short-term longitudinal study that spans a period of 14 weeks. This may seriously limit the effects of changes in FTP and PI on GP.

\section{Conclusions}

This study aimed to explore the possible changes in FTP and PI over a period of time as long as one academic semester, as well as to explore whether those changes in FTP and PI explain GP with regard to a specific course; educational psychology. The results of the present study demonstrated that some students' FTP and PI significantly changed over one academic semester according to the RCI analyses whereas some students' FTP and PI remained stable. This result indicates that the concept of change is more complicated than it has been assumed in educational settings. Therefore, not either change or stability, but both change and stability in students' FTP and PI should be considered in educational settings.

The results of this study also revealed that not those changes in students' FTP and PI, but lecturers' approaches to teaching significantly and considerably affected students' GP with regard to the educational psychology course, confirming the well-evidenced positive effects of student-centred approaches to teaching on student achievement. It can be suggested that student or learner-centred approaches to teaching should be preferred to affect students' GP in a positive way. Finally, overall results of this study pointed out that it is worth taking into consideration those changes as well as stability in FTP and PI in future research for a deeper analysis of student motivation and achievement in educational settings. 


\section{References}

Adelabu, D. H. (2007). Time perspective and school membership as correlates to academic achievement among African American adolescents. Adolescence, 42(167), 525-538.

Apostolidis, T., Fieulaine, N., \& Soulé, (2006). Future time perspective as predictor of cannabis use: Exploring the role of substance perception among French adolescents. Addictive Behaviors, 31, 2339-2343.

Bandura, A. (1997). Self-efficacy: the exercise of control. New York, NY: Freeman.

Bembenutty, H. (2009). Academic delay of gratification, self-regulation of learning, gender differences, and expectancy-value. Personality and Individual Differences, 46(3), $347-352$.

Bentley, A. M. (1983). Personal and global futurity in Scottish and Swazi students. Journal of Social Psychology, 121, 223-229.

Bollen, K. A., \& Curran, P. J. (2006). Latent curve models: A structural equation perspective. New Jersey, NJ: Wiley-Interscience.

Cate, R. A., \& John, O. P. (2007). Testing models of the structure and development of future time perspective: Maintaining a focus on opportunities in middle age. Psychology and Aging, 22(1), 186-201.

Cohen, J. (1977). Statistical power analysis for the behavioral sciences. New York, NY: Academic Press.

Creten, H., Lens, W., \& Simons, J. (2001). The role of perceived instrumentality instrumentality in students motivation. In A. Efklides, J. Kuhl, \& R. M. Sorrentino (Eds.), Trends and prospects in motivation research (pp. 37-45), New York, NY: Kluwer.

Daltrey, M. H., \& Langer, P. (1984). Development and evaluation of a measure of future time perspective. Perceptual and Motor Skills, 58(3), 719-725.

De Volder, M., \& Lens, W. (1982). Academic achievement and future time pesrpective as a cognitive-motivational concept. Journal of Personality and Social Psychology, 42, $566-571$.

Eccles, J. S., Wigfield, A., \& Schiefele, U. (1998). Motivation to succeed. In W. Damon (Series Ed.) and N. Eisenberg (Vol. Ed.), Handbook of child psychology (5th ed., Vol. III, pp. 1017-1095). New York: Wiley.

Eren, A. (2007). Gelecek zaman perspektifi ölçeği (The future time perspective scale). Ĕ̌gitim Bilimleri ve Uygulama Dergisi-Educational Sciences and Practice Journal, 6(12), 7996. 
Farris, P. J. (1996). Teaching, bearing the torch. Chicago: Brown \& Benchmark.

Ferrari, J. R., \& Diaz-Morales, J. F. (2007). Procrastination: Different time orientations reflect different motives. Journal of Research in Personality, 41, 707-714.

Fraenkel, J. R., \& Wallen, N. E. (2006). How to design and evaluate research in education. New York, NY: McGraw-Hill.

Fryer, J W., \& Elliot, A. J. (2007). Stability and change in achievement goals. Journal of Educational Psychology, 99(4), 700-714.

Gjesme, T. (1983). On the concept of future time orientation: Considerations of some functions and measurements' implications. International Journal of Psychology, 18, 443461.

Greene, B. A., \& DeBacker, T. K. (2004). Gender and orientations toward the future: Links to motivation. Educational Psychology Review, 16(2), 91-120.

Hoogstra, M. A., \& Schanz, H. (2008). The future orientation of foresters: An exploratory research among Dutch foresters into the prerequisite for strategic planning in forestry. Forest Policy and Economics, 10(4), 220-229.

Horstmanshof, L., \& Zimitat, C. (2007). Future time orientation predicts academic engagement among first-year university students. British Journal of Educational Psychology, $77,703-718$.

Husman, J., \& Shell, D. F. (2008). Beliefs and perceptions about the future: A measurement of future time perspective. Learning and Individual Differences, 18(2), 166-175.

Husman, J., \& Lens, W. (1999). The role of the future in student motivation. Educational Psychologist, 34(2), 113-125.

Jacobson, N. S., \& Truax, P. (1991). Clinical significance: A statistical approach to defining meaningful change in psychotherapy research. Journal of Consulting and Clinical Psychology, 59, 12-19.

Kaiser, H. F. (1960). The application of electronic computers to factor analysis. Educational and Psychological Measurement, 20, 141-151.

Kauffman, D. F., \& Husman, J. (2004). Effects of time perspective on students motivation: Introduction to a special issue. Educational Psychology Review, 16(1), 1-7.

Lang, F. R., \& Carstensen, L. L. (2002). Time counts: Future time perspective, goals, and social relationships. Psychology and Aging, 17(1), 125-139.

Lens, W. (2001). How to combine intrinsic task-motivation with the motivational effects of the instrumentality of present tasks for future goals. In A. Efklides, J. Kuhl, \& R. M. 
Sorrentino (Eds.), Trends and prospects in motivation research (pp. 23-36), New York, NY: Kluwer.

Leonardi, A. (2007). Future time perspective, possible selves, and academic achievement. New Directions for Adult and Continuing Education, 114, 17-26.

Levy-Tossman, I., Kaplan, A., \& Assor, A. (2007). Academic goal orientations, multiple goal profiles, and friendship intimacy among early adolescents. Contemporary Educational Psychology, 32(2), 231-252.

Lewin, K. (1951). Field theory in social science. New York, NY: Harper and Row.

Malka, A., \& Covington, M. V. (2005). Perceiving school performance as instrumental to future attainment: Effects on graded performance. Contemporary Educational Psychology, 30(1), 60-80.

Meade, R. D. (1972). Future time perspectives of Americans and sub-cultures in India. Journal of Cross-Cultural Psychology, 3, 93-99.

Miller, R. B., DeBacker, T. K., \& Grene, B. A. (1999). Perceived instrumentality and academics: The link to task valuing. Journal of Instructional Psychology, 26, 250-260.

Moé, A., \& Pazzaglia, F. (2006). Following the instructions!: Effects of gender beliefs in mental rotation. Learning and Individual Differences, 16(4), 369-377.

Moore, C., \& Lemmon, K. (2001). The self in time: Developmental perspectives. Mahwah, NJ: Erlbaum.

Neuman, W. L. (2006). Social research methods: Qualitative and quantitative approaches ( $6^{\text {th }}$ edition). New York, NY: Pearson.

Padawer, E. A., Lawson, J. M. J., Hershey, D. A., \& Thomas, D. G. (2007). Demographic indicators as predictors of future time perspective. Current Psychology, 26, 102-108.

Pagano, R. R. (2007). Understanding statistics in the behavioral sciences. Belmont, CA: Thomson Wadsworth.

Peetsma, T. T. D. (2000). Future time perspective as a predictor of school investment. Scandinavian Journal of Educational Research, 44(2), 177-192.

Phan, H. P. (2009). Future time perspective in sociocultural contexts: A discussion paper. Electronic Journal of Research in Educational Psychology, 7(2), 761-778.

Ramsden, P. (1993). Learning to teach in higher education. New York, NY: Routledge.

Seginer, R., \& Mahajna, S. (2004). How the future orientation of traditional Israeli Palestenian girls links beliefs about women's roles and academic achievement. Psychology of Women Quarterly, 28, 122-135. 
Seijts, G. H. (1998). The importance of future time perspective in theories of work motivation. Journal of Psychology, 132(2), 154-168.

Shell, D. F., \& Husman, J. (2001). The multivariate dimensionality of personal control and future time perspective in achievement and studying. Contemporary Educational Psychology, 26, 481-506.

Shell, D. F., \& Husman, J. (2008). Control, motivation, affect, and strategic self-regulation in the college classroom: A multidimensional phenomenon, Journal of Educational Psychology, 100(2), 443-459.

Slavin, R. (2003). Educational Psychology: Theory and practice. Boston: Allyn \& Bacon.

Simons, J., Dewite, S., \& Lens, W. (2004). The role of different types of instrumentality in motivation, study strategies, and performance: Know why you learn, so you'll know what you learn. British Journal of Educational Psychology, 74, 343-360.

Simons, J., Vansteenkiste, M., Lens, W., \& Lacante, M. (2004). Placing motivation and future time perspective theory in a temporal perspective. Educational Psychology Review, 16(2), 121-139.

Stouthard, M. E. A., Peetsma, T. D. (1999). Future-time perspective: Analysis of a facetdesigned questionnnaire. European Journal of Psychological Assessment, 15(2), 99105.

Tabachnick, B. G., \& Fidell, L. S. (2007). Using multivariate statistics ( $5^{\text {th }}$ edition). New York, NY: Pearson.

Teahan, J. E. (1958). Future time perspective, optimism, and academic achievement. Journal of Abnormal Social Psychology, 57(3), 379-380.

Toda, M. (1983). Future time perspective and human cognition: An evolutional view. International Journal of Psychology, 18, 351-365.

Ullman, J. B. (2007). Structural equation modeling. In B. G. Tabachnick \& L. S. Fidell (Eds.), Using multivariate statistics. New York, NY: Pearson.

Van Calster, K., Lens, W., \& Nuttin, J. R. (1987). Affective attitude toward the personal future: Impact on motivation in high school boys. American Journal of Psychology, $100(1), 1-13$.

Vroom, V. H. (1964). Work and motivation. New York, NY: Wiley.

Wallace, M. (1956). Future time perspective in schizophrenia. Journal of Abnormal and Social Psychology, 52, 240-245.

Weinberg, S. L., \& Abramowitz, S. K. (2002). Data analysis for the behavioral sciences using SPSS. New York, NY: Cambridge University Press. 
Wigfield, A., \& Eccles, J. S. (2000). Expectancy-value theory of achievement motivation. Contemporary Educational Psychology, 25, 68-81.

Yorke, M., \& Longden, B. (2004). Retention and student success in higher education. Berkshire, UK: Society for Research into Higher Education \& Open University Press.

Zimbardo, P. G., \& Boyd, J. N. (1999). Putting time in perspective: A valid, reliable individual-differences metric. Journal of Personality and Social Psychology, 77(6), 12711288.

Zimbardo, P. G., \& Boyd, J. N. (2008). The time paradox: the new psychology of time. London: Rider. 
Altay Eren

[This page intentionally left blank] 